\title{
Analogy in Classical Greece
}

The aim of this book is to analyse and defend the claim that the first four chapters of Darwin's Origin constitute an argument by analogy from artificial selection to natural selection, situating that argument in Darwin's thought as a whole: just as human beings by their selective practices in domestic settings can make new varieties of plants and animals, so the struggle for existence in the wild can make new varieties and even new species of plants and animals. This claim has been frequently made, but also latterly contested. However, both the defenders and the opponents rarely spell out in detail what the argument is supposed to be, and, insofar as they do so, usually work with an inappropriate account of what an argument by analogy is thought to be.

Therefore, before turning to Darwin himself, we need, in this chapter and the next, to examine the idea of an argument by analogy. We begin in classical Greece where the concept of analogy was introduced, before turning in the next chapter to the emergence of a completely different conception of analogy, and with it a completely different account of argument by analogy. We shall argue that although the later account has become the most popular understanding of 'argument by analogy', it is the classical account which is the appropriate one to account for the text of the Origin.

The point is that the word 'analogy' has historically been understood in two quite different ways. The word was initially introduced in Pythagorean mathematics (' $\alpha v^{\prime} \alpha \lambda_{0} \gamma l \alpha$ ') and then extended into the empirical domain, above all by Aristotle. Here, the word always designated a proportionality ('A is to B as C is to D'), and the interest was in the rich variety of uses to which appeals to analogies of this kind could be put, as against simple similarities ('A and B share some intrinsic properties'), whose uses were very limited. The contrast between analogy and simple similarity was always observed and insisted upon. However, beginning in the seventeenth century, in large part as a reaction against mediaeval scholasticism, this 
contrast was ignored - or, at most, it was noted that this distinction was important but only in mathematics. Elsewhere 'analogy' was treated as a near synonym for 'similarity'. Insofar as the two were distinguished, it was not in accord with Greek usage, but talking of 'analogy' was treated as most appropriate when A and B shared several similarities.

Corresponding to these two different ways of understanding the word 'analogy' were two completely different accounts of what constituted an argument by analogy. Without at this stage analysing them in detail, we may look at the following two supposed uses of 'argument by analogy'. Consider first the following 'anti-democratic' argument ascribed by Aristotle to Socrates, ${ }^{\mathrm{I}}$ where Socrates is protesting against the use of a form of lottery in the appointment of certain offices of state (a procedure deemed 'democratic' because every citizen had the same chance of holding office):

We ought not to choose our magistrates by lot, since this would be like choosing the athletes to represent us at the Olympic Games by lot rather than by their skill at athletics, or like sailors choosing their helmsman by lot, rather than one with the relevant knowledge.

When we realise why it would be absurd to choose athletes or helmsman by lot, since there are skills vital to being a successful athlete or helmsman, we see that by analogy it is absurd to choose magistrates by lot. What we have here is an argument by analogy that is valid, given the tacit premise that there is a range of skills necessary to carry out the tasks of a magistrate successfully.

Contrast this with:

This berry shares a large number of characteristics with a berry known to be poisonous. Therefore it is probable that it is also poisonous. The more characteristics it shares, the more probable it becomes that it is poisonous.

Both of these arguments clearly need tightening up: in the first case, we need to show that the analogy holds in all relevant respects, and in the second, we need, for instance, to find a way to exclude characteristics that are irrelevant to the point at issue. But even after tightening up, what we have here are two radically different arguments. The first argument can be developed into a fully valid argument, but the second, though not worthless - it is obviously sensible to avoid the berry - is at best a probabilistic argument, beset with difficulties in attempting, for example, to quantify

${ }^{\text {I }}$ Rhet., II. I393a 23-I393b 7. 
the probabilities involved. Because of this, it is clearly crucial when we come to examine Darwin's presentation of his argument by analogy in the first four chapters of the Origin to be clear which of these two patterns of argument is involved. This is particularly true since the vast majority of commentators, both those claiming that these chapters do constitute an argument by analogy and those who contest this, have assumed that there is thereby meant an argument of the second sort, whereas it is the central contention of this book that a careful examination of Darwin's text shows him as presenting a near perfect argument of the first sort.

Therefore, before turning to our main subject - an exegesis of Darwin's use of the analogy - we look further at the two different forms of argument. In this chapter, we look at the introduction of analogy as proportionality in classical Greece, including the prototype of the first form of argument by analogy, the development in Euclid VI of the theory of similar triangles, and hence, by extension, the simplest of all analogical models - the scale model. Then in the next chapter, we look at the centuries immediately prior to the Origin, where we find two things: the emergence and eventual great popularity of the second form of argument, while alongside this we shall see continued exploration of analogy as classically understood, culminating in the work of Richard Whately, and following him John Stuart Mill.

\section{The First Introduction of the Concept of Analogy}

\section{Euclid V: Analogy and Incommensurable Magnitudes}

The analogical relationship, interpreted as the identity of the relative magnitudes of two lengths $(\mathrm{A} / \mathrm{B}=\mathrm{C} / \mathrm{D})$, first appears in Greek mathematics as an element in Pythagoras' theory of musical harmonics. However, for our purposes, we are concerned with a later use in which it becomes a key concept in Euclid V where it has a fundamental role in the solution to the problem posed by the discovery of incommensurable magnitudes, thereby marking a key stage in the development of mathematics.

The problem of incommensurable magnitudes arises as follows. We start out with the Pythagorean theory of relative magnitude, which says that we can specify the relative magnitude of any two lengths by two whole numbers (at this stage the phrase 'whole numbers' is pleonastic - the only numbers recognised are the positive whole numbers). Thus, for any two lengths, $A$ and $B,(\exists m)(\exists n)(m A=n B)$, where, importantly, this formula 
can be given a straightforward geometrical interpretation: if you extend A to $\mathrm{m}$ times its length and $\mathrm{B}$ to $\mathrm{n}$ times its length, you arrive at two lines that are the same in length.

However, this simple theory received a death blow with the discovery of incommensurable magnitudes - the discovery that it was possible to construct a pair of lines for which it was impossible to satisfy this formula. The proof of this was a simple corollary of Pythagoras' theorem. Consider an isosceles right-angled triangle, with hypotenuse of length $\mathrm{H}$, sides of length S. By Pythagoras' theorem, $\mathrm{H}^{2}=2 \mathrm{~S}^{2}$. If the Pythagorean theory of magnitude is correct, there exist two numbers $\mathrm{p}$ and $\mathrm{q}$ such that $\mathrm{H} / \mathrm{S}=\mathrm{p} / \mathrm{q}$ where $\mathrm{p}$ and $\mathrm{q}$ have no common factors, from which it follows that $\mathrm{p}^{2}=2 \mathrm{q}^{2}$. Now, the square of an odd number is odd, and of an even number even, so that $p$ must be even $=2 r$, say, giving $u s r^{2}=2 q^{2}$, or $4 r^{2}=2 q^{2}$, giving us in turn that $q$ must also be even, contradicting our assumption that $\mathrm{p}$ and $\mathrm{q}$ have no common factors.

This discovery constituted what may be regarded as the first crisis in the foundation of mathematics: it was now possible to specify lengths for which there could be no answer to the question of their relative magnitude. The task was thus to replace the Pythagorean theory of magnitude by one that was equally applicable to incommensurable and commensurable magnitudes. The two mathematicians who proposed solutions to this problem were Theaetetus, ${ }^{2}$ and Eudoxus of Cnidus. It is the latter who concerns us here, and specifically the opening definitions in Euclid Book $\mathrm{V}$ that have been traditionally ascribed to Eudoxus. The most relevant definitions for our purposes are the following:

Definition 3. Ratio is a mutual relation of two magnitudes of the same kind to one another in respect of quantity.

Definition 5. The first of four magnitudes is said to have the same ratio to the second, that the third has to the fourth, when any equimultiples whatever of the first and third being taken, and any equimultiples whatever of the second and the fourth, if the multiple of the first be less than that of the second, the multiple of the third is also less than that of the fourth, and if the multiple of the first be equal to that of the second, the multiple of the third is also equal to that of the fourth, and if the multiple of the first be greater than that of the second, the multiple of the third is also greater than that of the fourth.

Definition 6. Magnitudes which have the same ratio are called proportionals (analogous). When four magnitudes are proportionals (analogous),

\footnotetext{
${ }^{2}$ His solution to the problem is to be found in Euclid Book X.
} 
it is usually expressed by saying the first is to the second as the third is to the fourth.

Definition 8. Analogy, or proportion, is the similitude (equality) of two ratios.

In the first of these, definition 3, where initially the notion of a ratio is left to be specified further in the subsequent definitions, the important thing to notice is the phrase 'of the same kind to one another' - you can talk of the ratio of one length to another length, or the ratio of one time to another time, but not of the ratio of a time to a length. It is the abandonment of this restriction when we come to extend analogy beyond its mathematical application that marks what is the most significant difference between the mathematical and the non-mathematical concepts of analogy.

The key definition is definition 5, which may be easier to understand if we render it in modern notation:

Given four magnitudes $A, B, C$ and $D, A / B=C / D$ if and only if the following condition is satisfied:

$$
\begin{gathered}
(\forall \mathrm{m})(\forall \mathrm{n})((\mathrm{m} \times \mathrm{A}>\mathrm{n} \times \mathrm{B} \rightarrow \mathrm{m} \times \mathrm{C}>\mathrm{n} \times \mathrm{D}) \\
\&(\mathrm{~m} \times \mathrm{A}<\mathrm{n} \times \mathrm{B} \rightarrow \mathrm{m} \times \mathrm{C}<\mathrm{n} \times \mathrm{D}) \\
\&(\mathrm{~m} \times \mathrm{A}=\mathrm{n} \times \mathrm{B} \rightarrow \mathrm{m} \times \mathrm{C}=\mathrm{n} \times \mathrm{D}))
\end{gathered}
$$

where the quantifiers range over the natural numbers.

The strategy adopted here anticipates the strategy that was used in the nineteenth century to define real numbers. There you specify a real number by specifying which rational numbers are greater than it, which less, and which equal to it. Here you specify a relative magnitude by specifying which commensurable relative magnitudes are greater than it, which less, and which equal to it. The basic strategy here, which represents the high point of Greek mathematics and paves the way for modern mathematics, may be put as follows: it has been shown that we cannot in general specify the relative magnitude of any two lengths by citing a simple arithmetical formula for that magnitude, but we can nevertheless specify the relative magnitude of an arbitrary pair of lengths in the following sense. We can say when that relative magnitude is the same or different from the relative magnitude of any other pair of lengths. That is to say, we give the truth conditions of the formula $A / B=C / D$. This breakthrough was widely celebrated and led to a widespread interest in the concept of analogy, including, as we shall see, interest in the possibility of extending the concept beyond the realm of mathematics. 
Of course, the central mathematical interest here is the way that it gives us a general theory of magnitude at an altogether more sophisticated level than the Pythagorean theory that it replaces. However, for our purposes, we are concerned with other features of the formula $A / B=C / D$ that emerge in the course of the subsequent mathematical investigations. Primarily we are interested in the way in which in Euclid Book VI this formula is used in the construction of analogical models and the development of a style of argument by analogy that will concern us throughout this book, including providing a clue to the form of the argument of the Origin. But before turning to that, there are two other features of the formula $\mathrm{A} / \mathrm{B}=\mathrm{C} / \mathrm{D}$, as defined by Eudoxus, which are also important for our purposes.

In the first place, one key characteristic of the idea of a ratio, as we have been looking at it so far, is the restriction contained in the phrase 'magnitudes of the same kind'. So that, for instance, it permits us to compare one length to another, one time to another, one volume to another and so on, but not one length to a time. However, we frequently in fact want to compare things in different categories. To take a simple example, to arrive at a concept of velocity requires us to compare the distance travelled to the time taken. It is the concept of analogy, as just explained in definition 5, that permits us to make sense of such comparisons between things in different categories. If we look again at that definition

$$
\begin{gathered}
(\forall \mathrm{m})(\forall \mathrm{n})((\mathrm{m} \times \mathrm{A}>\mathrm{n} \times \mathrm{B} \rightarrow \mathrm{m} \times \mathrm{C}>\mathrm{n} \times \mathrm{D}) \\
\&(\mathrm{~m} \times \mathrm{A}<\mathrm{n} \times \mathrm{B} \rightarrow \mathrm{m} \times \mathrm{C}<\mathrm{n} \times \mathrm{D}) \\
\&(\mathrm{~m} \times \mathrm{A}=\mathrm{n} \times \mathrm{B} \rightarrow \mathrm{m} \times \mathrm{C}=\mathrm{n} \times \mathrm{D}))
\end{gathered}
$$

we see that although we can only give a meaningful interpretation of it if $A$ and $B$ are 'of the same kind', there is no reason why A and $C$ need be of the same kind. Thus whereas a theory of magnitude expressed purely in terms of ratios would make it impossible to compare a distance with a time, once we replace the Pythagorean theory with a theory expressed in terms of analogy, we can make sense of comparisons between things in different categories, and thus, e.g., find it possible to construct a concept of velocity, which precisely rests on comparing the distance travelled and the time taken. This leads us to an idea that, as we shall see, is stressed by Aristotle and indeed is crucial for making sense of subsequent applications of analogy, including those which we find in the Origin: there are two different ways of comparing two entities $A$ and $B$. The first, a direct comparison, only enables us to compare $A$ and $B$ if they are the same sort of thing, but 
the second, an indirect comparison resting upon an introduction of two other terms, $C$ and $D$, and using the formula ' $A$ is to $C$ as $B$ is to $D$ ', enables us to compare entities that, as Aristotle puts it, are remote, whether a distance to a time, an elephant's trunk to a hand, the opening chapters of a book to the opening shots in a battle, or a desert permitting only the most drought-resistant plants to survive to a racehorse owner permitting only the fastest horses to go to stud.

\section{The Alternation of Analogies}

In the second place, we should note here one of the basic features of the analogical relationship that will turn out to have particular relevance to a full understanding of Darwin's argument for the competence of natural selection to explain the emergence of new species. Analogies alternate. That is to say, if $A$ is to $B$ as $C$ is to $D$, then $A$ is to $C$ as $B$ is to $D$. There is an elegant proof at Euclid V, Proposition I6, that this follows from the definition of analogy given in definition 5. The account of analogy throughout Book V has as its premise that the four terms of the analogy are 'of the same kind'. However, we shall later be concerned with an extension of this to cases where the terms of the analogy are not of the same kind. At this stage, we simply note that the possibility of alternating analogies with heterogeneous terms is exploited widely even within mathematics. Consider again the way in which we arrive at the concept of velocity. If body $A$ travels a distance $d_{I}$ in time $t_{I}$, and body $B d_{2}$ in time $t_{2}$, where $d_{1} / d_{2}=t_{1} / t_{2}$, then, alternating the analogy, the velocity of $A$, $\mathrm{d}_{\mathrm{I}} / \mathrm{t}_{\mathrm{T}}$, will equal the velocity of $\mathrm{B}, \mathrm{d}_{2} / \mathrm{t}_{2}$.

The difference between the homogeneous case and the heterogeneous case is as follows. In the homogeneous case, we have the relation of A to $\mathrm{B}$ is the same as that of $\mathrm{C}$ to $\mathrm{D}$, where all four terms are of the same kind. More explicitly $\mathrm{ARB}=\mathrm{CRD}$. What is proved in Euclid V is that in this case, $\mathrm{ARB}=\mathrm{CRD} \rightarrow \mathrm{ARC}=\mathrm{BRD}$. However, in the heterogeneous case, because $\mathrm{A}$ and $\mathrm{C}$ are different in kind, ARC will typically make no sense. What we have is the weaker claim that there is a relation $R^{\prime}$ such that $\mathrm{ARB}=\mathrm{CRD} \rightarrow \mathrm{AR}^{\prime} \mathrm{C}=\mathrm{BR}^{\prime} \mathrm{D}$, where it is determined contextually, on a case by case basis, what the appropriate value for $R^{\prime}$ is.

\section{Euclid VI: Similar Triangles and Argument by Analogy}

In Book $\mathrm{V}$ the basic properties of analogy, understood in its original mathematical sense of the equality of two ratios of lengths, were explored, in order to develop various applications of analogy in subsequent books. 
For our purposes, what interests us is the way we can use the concept of analogy first to develop a concept of an analogical model, and then use that to explain a basic form of argument by analogy.

An analogical model may be explained as follows: suppose we have two domains of entities, and we set up a correspondence between entities in the one domain with entities in the other, thereby using the one domain as a model for the other. This model is an analogical model if there are a series of analogies between pairs of entities in the one domain and the corresponding pairs in the other. This is easiest to explain and understand by looking at the specific case that we find in Euclid Book VI.

Within Euclid, we are concerned with the simplest of all analogical models - the scale model, and, indeed the simplest of all scale models, two similar triangles. The central theme of Book VI is the theory of geometrically similar figures and of similar triangles in particular. Two triangles $\mathrm{ABC}$ and $\mathrm{A}^{\prime} \mathrm{B}^{\prime} \mathrm{C}^{\prime}$, with sides of lengths $\mathrm{a}, \mathrm{b}, \mathrm{c}$ and $\mathrm{a}^{\prime}, \mathrm{b}^{\prime}, \mathrm{c}^{\prime}$ will be similar if and only if $a / a^{\prime}=b / b^{\prime}=c / c^{\prime}$ : that is to say, if in accordance with the above definition, one is the analogical model of the other. We have made one triangle a model of the other by correlating the sides of the one triangle with the sides of the other. If the multiple instances of the analogical relation hold, then the triangles are similar, or, in other words, the first triangle is an analogical model of the second. Although this case is of extreme simplicity, its interest lies in the way that it can be readily extended to explain what it is for any two geometrical figures, of arbitrary complexity, to be similar to each other. The point of the concentration upon the case of similar triangles is that, since a triangle is the simplest rigid figure bounded by straight lines, a theory of similar triangles can readily be extended to a theory of geometrically similar figures in general: two figures will be geometrically similar if and only if every triangle inscribed in the first figure is similar to the corresponding triangle inscribed in the second. In this way we arrive at a general theory of what it is for one geometrical configuration to be a scale model of another.

We then proceed to prove that certain properties of the one triangle will be preserved by the modelling: that is, those properties will automatically be properties of the second, the most obvious such property being that corresponding angles of the two triangles will be equal, or that parallel lines correspond to parallel lines. Here we have a case of deductively valid analogical arguments, in which given that two geometrical figures are similar, we infer a range of additional properties that the two figures must have in common. 
We can see the power of this style of argument by analogy if we reflect on one of its most familiar applications - the construction of maps of a terrain by triangulation. The map is constructed by creating a network of triangles on the page, each of which is similar to a corresponding triangle in a network of triangles on the ground. Once a map has been properly constructed in this way, the configurations on the map will share a wide range of additional topological features with the configurations on the ground. It is precisely this fact that gives maps their utility. Thus, for instance, when you say, 'These two dots on the map are separated by a blue line; therefore to get from this town to that town you must cross a river', you are in fact drawing a valid analogical inference (with, of course, the tacit premise that the map has been properly constructed).

What we have here is the basic form of a valid argument by analogy:

Domain A is an analogical model of domain B

$\mathrm{F}$ is a feature of domain $\mathrm{A}$

Being $\mathrm{F}$ is invariant under analogy

$\therefore \mathrm{F}$ is a feature of domain $\mathrm{B}$.

What we need eventually to understand is what happens to such a pattern of argument when we transpose it from its mathematical setting to an empirical application. We can at this stage summarise the continuities and discontinuities involved in such transposition. We clearly have a valid argument form, regardless of its application. The difference lies in the question of the soundness of the argument, that is to say, the issue of the truth of its premises, and in particular whether we do have a genuine analogical model and whether the feature that interests us is indeed invariant under analogy. In the case of the similar triangles in Euclid, these premises are guaranteed a priori. We may simply posit at the outset that we are dealing with two similar triangles; we then go on to give a series of geometric proofs settling the question which features are indeed invariant under analogy. Once we move outside mathematics, arguments by analogy are only sound if we can give empirical support to, or other strong grounds for, accepting these premises. The reason that people are dubious as to the probative value of arguments by analogy is largely due to the widespread neglect on the part of those putting forward such arguments to give adequate grounds for believing precisely these premises. We shall seek to show that by contrast, Darwin's use of argument by analogy is fully responsible in this respect. 


\section{Archytas of Tarentum: Analogy and Definition}

Almost all of the ideas necessary for the analysis of the argument of the Origin can already be derived from that which we have found in Euclid, and that argument is simply an application of the argument by analogy that we found in the case of similar triangles. However, within Euclid, the formula ' $\mathrm{A}$ is to $\mathrm{B}$ as $\mathrm{C}$ is to $\mathrm{D}$ ' is always to be interpreted in purely mathematical terms - 'the ratio of $\mathrm{A}$ to $\mathrm{B}=$ the ratio of $\mathrm{C}$ to $\mathrm{D}$ '. For our purposes, we need to be able to give other, empirical, interpretations of this formula. We therefore need to look at subsequent developments in Greek thought to see whether and how we can extrapolate from the mathematical case to empirical interpretations of the analogical formula. Above all, we need to look at Aristotle's uses of analogy.

We look first at a use of analogy that is not prefigured in Euclid - the use of analogy to generate and define new concepts. For this, we need to consider Archytas of Tarentum. Archytas (428-347 BC) was a Pythagorean mathematician and statesman. Although only a few fragments of his writings survive, he is an important figure in the history of the concept of analogy. Not only was he a major influence on both Plato and Aristotle in their exploitations of analogy, it is in the slender evidence that survives that we find for the first time someone who is exploring the possibility of extending the concept of analogy beyond its original mathematical use.

His primary contribution, in the fragments for which we have evidence, is in the theory of definition, contained in these two quotations from Aristotle:

Similarly, the consideration of similarities is useful for forming definitions that cover widely differing subjects, e.g., 'Calm at sea and windlessness in the air are the same thing' (for each is a state of rest), or 'A point on a line and a unit in number are the same thing' (for each is a starting point). Thus, if we specify the genus to be that which is common to all the cases, the definition may be regarded as appropriate. This is how those who frame definitions usually proceed: they state that the point is the starting point of the line, the unit the starting point of number. It is clear that they are assigning them both to the genus of what is common to the two cases. ${ }^{3}$

It would seem that the definition by differentia is that of form and actuality, while that by constituent parts is, rather, that of matter. The same holds for the kind of definitions Archytas used to accept; for they are definitions combining matter and form. E.g., What is windlessness? Stillness in a large

${ }^{3}$ Top, I 108b23 ff. 
extent of air - the air is the matter, the stillness is the actuality and substance. What is a calm? Levelness of sea - the sea is the material substrate, the levelness, the actuality or form. ${ }^{4}$

Taking these two passages together, we may see Archytas as proposing a new way of defining concepts based upon analogy. We specify a concept not by noting properties belonging to all objects falling under that concept, but by grouping together as falling under a single concept a range of objects that are related analogically. Thus, to take one of Archytas' examples, the concept calm. We may talk of a calm sea, and a calm sky - and further of a calm mind, or of streets that are calm after a riot. These extremely heterogeneous entities have no obvious properties in common, but windlessness is to the sky as wavelessness is to the sea, as contentment is to the mind. Such concepts are extremely widespread, including open, long, difficult, principle, and typically permit us to group together objects that are different in kind (a long novel, a long pause, a long railway ...). It is clear that Archytas' approach has far greater explanatory power for such concepts than the frequent superficial appeal to 'family resemblances'.

This represents a major advance in the theory of definition. The then standard account had been offered by Plato - the method of division. There you began with a class and then subdivided until you had specified the concept required, producing definitions such as 'man is a rational, sensitive, animate substance'. Although this is an excellent start in the theory of definition, it is extremely limited in its application and very few scientifically fruitful concepts can be defined by this means. By contrast, a wide range of important concepts, both within and outside science, are susceptible of being explained along the lines outlined by Archytas. A major part of the greater power of such definitions - the part that will be stressed by Aristotle - is the capacity of such definitions to gather together and make scientifically significant comparisons between highly disparate phenomena.

When we come to the Origin, we shall find that two of Darwin's central concepts, 'struggle' and 'select', are paradigm cases of concepts that are best handled by Archytas' method.

\section{Plato: The Informal Use of Analogy}

Plato was a friend of Archytas, and was clearly familiar with his work. ${ }^{5}$ There is, however, not the rigorous use of analogy that we find either in

\footnotetext{
4 Meta, VIII I043a $22 \mathrm{ff}$.

5 For instance, the reference in "We may venture to suppose", I said, "that as the eyes are framed for astronomy so the ears are framed for the movements of harmony; and these are in some sort kindred
} 
the mathematics or that we shall encounter in Aristotle. There is also no theoretical discussion of the concept. What we find instead are several informal arguments by analogy based on an intuitive use of analogical models, such as 'the cave' ${ }^{3}$ and 'the line'. ${ }^{7}$ By looking at one, the most famous of these, we can see how we may transpose the idea of argument by analogy to a non-mathematical setting. This argument may be used to give us a preliminary indication of the form such an argument should take. Also, as it stands, Plato's argument is at best suggestive, and by seeing why it falls short of being a fully rigorous argument, we may use it to identify those features that would be required of such arguments by analogy to make them watertight.

The argument that we shall consider is the extended argument that constitutes the Republic. This argument is intended to demonstrate that it is better to be just than unjust. It is put forward as a reply to a challenge made by Glaucon and Adeimantus, who argue that, the nature of the world being such as it is, it is the perfectly unjust man who flourishes, but not only that, since he needs to appear to be just to carry out his nefarious schemes, he will become a benefactor of humankind. By contrast the perfectly just man will be condemned to a life of misery, and since he will not be concerned to appear to be just, will be constrained from behaving in ways that are to the obvious benefit of the rest of humankind.

The argument rests on using the state as an analogical model for the soul. We are then invited to infer that the ideal state having such-and-such a structure, so too the ideal for the soul will have an analogically corresponding state. The state is seen as having three components - a ruler, a group whose task is to ensure that the people obey the laws of the ruler, and the people. In the ideal state, the ruler will be the philosopher king, who knows 'the form of the good' - what is right should be done, and then there are guardians who have true beliefs about what should be done and whose task is to make the general public carry out the wishes of the king. It is then argued that the soul has also three components - reason, a 'spirited' part, and appetite. This is shown by the fact that we are sometimes torn between different courses of action, and in particular between what reason dictates that we ought to do, and what our appetites tell us that we want to do, and, further that in such cases we can by an act of will control our appetites. This enables us to use the state as an analogical model for the

sciences, as the Pythagoreans affirm and we admit, do we not, Glaucon?"' (Republic, 53od) has been ascribed to Archytas.

${ }^{6}$ Republic, 514a-520a. $\quad 7$ Republic, 509d-5i Ie. 
human soul. We then argue that just as the best state - the just state - is one in which the philosopher king is in power and the guardians ensure his laws are obeyed, so the best soul - the just soul - is one in which reason always controls the passions.

There is clearly much that is questionable about this argument. Is a society in which the majority of the people have no control over their lives and are simply made to do what the ruler dictates really an ideal society? However, we are concerned with the question how well the argument stands up as an analogical argument. That will give us a preliminary indication of what needs attending to in assessing any purported analogical argument. Even if we grant Plato his premise that he has shown the republic to be the just society - that is not our present concern, which is whether if we accept that as a premise, he is entitled to infer his conclusions as to what it is for the soul to be just. If we were to accept Plato's argument we would clearly need to be satisfied about two things. Firstly, we would need to ask whether we have here a genuine case of an analogical model. That is to say, is it really the case that the relation between a ruler and the citizens was the same as the relation between reason and appetites in the soul: that the ruler: the citizens :: reason: appetite? To be convinced of that we would need to accept Plato's argument that the best way to explain being torn in different directions as to what to do is to hypostasise three different aspects of the soul, in such a way that we can take seriously the idea of one of these aspects governing another. Secondly, once we had established that there was indeed an analogical model here, we would then need to show that being just was a feature that was invariant under analogy - that if the state were just, it would follow that a soul with the corresponding structure would also be just. It is here perhaps that the argument is most vulnerable: there is something like an equivocation on the word 'just' here. We are talking about something very different when we describe a state as just and when we talk about an individual as just. For a state to be just is for there to be just treatment of the citizens within the society, for instance, for there to be equality before the law; however, for an individual to be just concerns their relations with other people: in one case we are concerned with the internal relations within the state, in the other with the external relations of the individual.

\section{Aristotle: Two Ways of Comparing Things}

It is in the use that Aristotle makes of the concept of analogy, rather than the more informal uses that we find in Plato, that we find the full potential 
of the concept once it is extended beyond its mathematical origins. Aristotle shows how appeals to analogy can be made to do important work in research in the varied contexts - in rhetoric, in his researches into living things, in metaphysics, in the theory of justice and in the theory of definition. In each of these cases, he is typically precise and rigorous, with a surefooted understanding of what analogy can, and cannot, do for us. However, for our purposes, we shall not look in detail at each of these particular applications: only two of these applications will prove to be of importance in eventually understanding the role of analogy in the Origin: that of the relation of analogy to metaphor, and that of the question of method in biology. ${ }^{8}$ We shall look at Aristotle on metaphor in the course of Chapter 6, and before looking at the biological writings, we shall identify and examine some of the themes that recur in all these applications.

We begin with what may be regarded as a key theoretical statement: 'Yet a further method of selection is by analogy: for we cannot find a single word applicable to a squid's pounce, fish spine and bone, although these too possess common properties as if there were a single osseous nature. ${ }^{\prime 9}$ In a way this is simply a repetition of what we found in Archytas, but it is worth interpreting it in the context in which Aristotle introduces the idea. The major part of the Posterior Analytics is concerned with definition by the method of division, where a definition proceeds by taking a large class, dividing it, then subdividing until you have specified the class of things that interest you, producing such definitions as 'Man is a rational, sensitive, animate substance'. He is working here against a Platonic background, in which there were ways of 'carving nature at the joints', ${ }^{\text {IO }}$ producing natural kinds, and where natural kinds could always be defined by the method of division.

But at the same time, even at the stage of his enquiry represented by the Posterior Analytics, there is something that will assume central significance in the Parts of Animals: even within the science of biology there is a need for concepts that do not pick out natural kinds. He proposes that such concepts can be defined by analogy, along the following lines. We start by defining the species of animals by the method of division, setting up a Porphyry tree branching downwards, with the different species at the bottom. We then cut across the tree picking out functionally

8 The word 'biology' is of course a much later invention, but as with most Aristotelian specialists, we may apply it to Aristotle as giving an accurate picture of the nature of his investigations.

9 PostA, II. 98a 20 io Phaedrus, 265 e. 
corresponding parts of different animals. In the example he gives, we take the example 'bone', where we have monkey bone, fishbone and cuttlebone. These are composed of completely different substances and thus do not form a natural kind. They are however analogically related: monkey bone is to monkeys as fishbone is to fishes and as cuttlebone is to cuttlefish, in that in each case we are dealing with substances that can provide the skeletal structure for their host. In order to provide such a skeletal structure, they must share those properties, such as hardness, that are necessary or useful in performing their function. In this way, we arrive at an 'as-if natural kind, which can be the subject of scientific investigation. ${ }^{\text {II }}$

Likenesses must be studied between things in different genera, the formulae for such likenesses being 'As $A$ is to $B$, so is $C$ to $D$ ', such as 'As knowledge is to what is known, so is sensation to what is sensed', and also 'As $A$ is in $B$, so is $C$ in $D$ ', such as 'As sight is in the eye, so is reason in the soul', or, 'As wavelessness is in the sea, so is windlessness in the air'. In particular, we must have practice in comparing genera which are remote; for in the other cases, the similarities will be more readily apparent. ${ }^{\text {I2 }}$

The governing idea that runs through all the diverse applications that Aristotle makes of the concept of analogy is that there are two fundamentally different ways of comparing two things, A and B: there is, firstly, making a direct comparison, which is a matter of noting common properties of $\mathrm{A}$ and $\mathrm{B}$, and secondly, making an indirect comparison, in which we introduce third and fourth terms, C and D, such that A is to C as B is to $\mathrm{D}$. This contrast is highly flexible and may be adapted in a way that is appropriate to the topic of research. Thus, Aristotle shows how exploitation of this contrast can illuminate questions concerning the nature of justice, explain the difference between successful metaphors and lifeless metaphors, be fundamental to comparative anatomy and throw light on the question what could be meant by equality in the state. In each of these examples, the analogical relation 'A: B :: C: D' is to be understood in a way that fits the topic in hand. In every case apart from metaphor, it is clear how the formula is to be interpreted and Aristotle holds rigorously to that

I Given that we now, unlike Aristotle, believe that biological entities are the products of a partly random and chaotic process, it becomes even more urgent to explain the possibility of biology as a science when few, if any, of its concepts, such as 'species' or 'law' pick out natural kinds. It is at least worth exploring the question whether Aristotle's proposal that analogy can be used to explain such 'as-if natural kinds can be worked out.

I2 Top, I. Io8a $6 \mathrm{ff}$. 
interpretation. ${ }^{13}$ Thus in the case of justice and equality in the state, Aristotle contrasts arithmetical equality - everyone is paid the same and analogical equality in which everyone is paid proportionally to their role within society; in the case of metaphor, we have a contrast between metaphors based upon a transfer from species to species or genus to species and metaphors based on analogy; and in his researches into living things there is a contrast between parts of animals that differ by the more and the less and parts of animals that are only related by analogy.

One element in the quotation we are now looking at is the idea that analogical comparison, unlike a direct comparison, permits us to compare 'genera that are remote'. Here the word 'remote' should be read as broadly as one chooses: no matter how different in kind two entities may be, an analogical comparison between them may still be possible. We already saw this when we looked at Euclid, showing how Eudoxus' definition of analogy permitted us to arrive at a concept of velocity by comparing time taken with distance travelled. When we move outside the mathematical context, everyday examples clearly show this to be true. An opening batsman at cricket, the opening chapter of a book, a chess opening and the opening of a new hospital: here we have four entities that share no obvious intrinsic properties that can nevertheless be fruitfully seen as all openings because of the way that they are related to what is to follow. Aristotle himself will show how this can be exploited, e.g., in his theory of justice. ${ }^{\mathrm{I}}$ Suppose you wish to explain what a fair price is for something. You constantly have to compare things that are remote - the price of a house and the price of legal representation in court. A direct comparison of goods that are so different is virtually impossible. Aristotle therefore proposes that we explain a fair exchange by finding an interpretation of the analogy: this much legal representation is to the lawyer as a house is to the builder - e.g., how much it costs each to produce their respective goods.

Finally, Aristotle is claiming that it is the analogical comparisons, as opposed to the direct comparisons, that will characteristically be the scientifically fruitful comparisons. Thus when we come to look at Darwin's use of analogy, whereas comparing the activities of one breeder with another simply tells much the same story, it is the comparison between a farmer castrating a bull and frost killing a lettuce that leads to the idea of natural selection.

${ }^{13}$ In the case of metaphor, we are dealing with an essentially unsystematic and opportunistic use of analogy.

${ }^{14}$ See, e.g., $N E$, I I 33 a 6, I I 


\section{Analogy in Biology}

Aristotle's contribution to the early history of biology is one of his most assured accomplishments with a deep influence on all his successors until Darwin, so that even someone as late as Cuvier will explicitly describe himself as applying Aristotle's methods in his work. Darwin himself writes in such a way as to indicate that he regarded Aristotle as the greatest of his predecessors. ${ }^{15}$ There is a widespread opinion that Darwin's work made Aristotle's work obsolete. However, that is a simplistic reaction. What is clear is that Aristotle had argued for the fixity of species, and as a result could only account for the high level of functional complexity evident in animals, by positing as an underlying metaphysical principle that nature itself was purposive, leading to the methodological principle that 'nature does nothing without purpose or makes anything superfluously'. ${ }^{16}$ The theory of evolution by natural selection enables us to replace the highly counterintuitive metaphysical principle that Aristotle found himself forced into by a simple, purely naturalistic interpretation of the purposiveness that is evident throughout the animal kingdom.

However, even if the metaphysical background to Aristotle's account of animals and plants may be regarded as refuted by modern evolutionary theory, that leaves the method for biological research that he argues for untouched. As a pioneer, working with limited empirical information, it is inevitable that Aristotle will frequently go wrong in the conclusions that he draws. However in subsequent centuries, further empirical investigations making more refined application of Aristotelian methods are responsible for a large proportion of the advances in pre-Darwinian biology, such as, for example Harvey's discovery of the circulation of the blood.

Unlike previous explorations in biology, and indeed his own investigations in the Posterior Analytics, in his biological writings properly speaking, Aristotle shows little interest in the question of definition. At Parts of Animals $642 \mathrm{~b} 5 \mathrm{ff} .$, he makes a long series of devastating criticisms of the attempt to define animals by the method of dichotomous division, and that is all. Instead, he sets himself a different task, that of discovering why animals are the way they are, where this question must be interpreted in terms of discovering their 'final causes'. That is to say, the kind of

\footnotetext{
is Letter to William Ogle, February, I 882: 'From quotations which I had seen, I had a high notion of Aristotle's merits, but I had not the most remote notion what a wonderful man he was. Linnaeus and Cuvier have been my two gods, though in very different ways, but they were mere schoolboys to old Aristotle.' For the relation of Darwin to Aristotle, cf. Gotthelf (I999), pp. 3-30.

${ }^{16} P A$, II $65 \mathrm{Ib} 24$.
} 
explanation he is after is illustrated by the reply to the question 'Why do giraffes have long necks?', 'So that they can browse the leaves of tall trees'.

To understand how he is to set about offering answers to such questions, we must first look at the way that he is thinking of animals. They are for him the paradigm case of substances, entities that are systems of parts, whose continued existence depends upon the cooperative activity of those parts. They are composed of matter, the stuff they are made of, and form, the principle of organisation of the parts to produce a functioning whole. In the case of living substances, the form of the being is what Aristotle calls its 'soul'.

This conception is clarified by the simple observation that Aristotle makes at the beginning of the Parts of Animals. There is a range of things that an animal needs to do if it is successfully to live out its life (and reproduce): 'For genera that are quite distinct still frequently present many identical phenomena, sleep, for instance, respiration, growth, decay, death, and other similar affections and conditions, which may be passed over for the present, as we are not yet ready to treat of them with clearness and precision'. ${ }^{17}$

If an animal can perform such actions, it must be assembled in such a way that enables it so to do. A part may then be identified functionally, as organ, $^{18}$ as the feature of the animal that gives it the ability to do certain things.

In the light of this, Aristotle's question now becomes the questions 'Why does an animal have the parts it does?' and 'Why do these parts have the form they have, and why are they related the way they are?' To answer such questions, Aristotle makes what is perhaps his most significant contribution to the theory of life, the use of comparative biology. One compares corresponding organs in different species of animals. The similarities between these organs give one a guide as to what is necessary for such an organ to carry out its function, or at least carry out that function well. The differences give one a guide as to the way that such organs are adapted to fit the life of the particular animal.

This enquiry is governed throughout by a major contrast between the ways in which corresponding organs are related: they either 'differ by the more and the less' or are 'related only by analogy'. The term 'differing by the more and the less' stems from Plato ${ }^{19}$ to signify cases where two things possess the same property but to different degrees. Two things will thus

${ }^{17} P A 639 a, 19-23 \quad{ }^{18}$ 'Organon' is Aristotle's metaphor. The word literally means a tool.

19 Philebus, 24a-25d. 
'differ by the more and the less' if all the differences between them can be specified simply by the use of comparatives: one is longer, heavier, hotter ... than the other. We can see the straightforward biological application of this idea if we consider the case of beaks. Given any two birds, when we compare their beaks, we find basically the same structure, composed of the same stuff, but in the one case the beak is longer, straighter, more pointed ... than the other. By way of contrast, if we consider the case of the horns and tusks of different animals, we have the same kind of organ of defence, but with far greater differences than can be specified simply by the use of the more and the less. These organs are related by analogy, in that they have the same function: horns are to bulls as tusks are to elephants.

The two different ways in which organs are related play opposite roles in Aristotle's investigations. In the case of parts that differ by the more and the less it is the difference between the parts that are significant but in the case of parts that are related only by analogy, it is the similarities.

In the case of parts that differ by the more and the less, the differences show one the way in which the parts have been fine-tuned to fit the way of life of the various animals:

Various sorts of beak are found, to suit the various uses including defence to which it is put. All of the birds known as crook-taloned have a curved beak, because they feed on flesh and take no vegetable food: a beak of this form is useful to them in overcoming their prey, as better fitted for the exertion of force. ... Every bird has a beak which is serviceable for its particular mode of life. The woodpeckers, for instance, have a hard beak ... small birds, on the other hand, have finely constructed beaks, for picking up seeds and catching minute animals. ${ }^{20}$

In the case of parts related by analogy, despite the fact that they are related only by analogy, they will typically also possess a range of common intrinsic properties. These are the properties that an organ of that kind must have if it is to function, or at least function well. Thus if we look at the case of an elephant's tusk and a bull's horn, they are, for instance both curved, pointed, of the same texture and attached to the head. By reflecting on such common properties as our investigations identify, we can further our understanding of the part and its function.

Again, Nature acted rightly in placing the horns on the head. Momus in Aesop's fable is quite wrong when he finds fault with the bull for having his horns on the head, which is the weakest part of all, instead of on the shoulders,

\footnotetext{
${ }^{20} P A$ III 662b, I-Io.
} 
which, he says, would have enabled them to deliver the strongest possible blow. Such a criticism shows Momus' lack of perspicacity. If the horns had been placed on the shoulders, as indeed on any other part of the body, they would have been a dead weight, and would have been no assistance but rather a hindrance to many of the animal's activities. And besides, strength of stroke is not the only point to be considered: width of range is equally important. Where could the horns have been placed to achieve this? It would have been impossible to have them on the feet, knees with horns on them would have been unable to bend; and the bull has no hands; so they had to be where they are - on the head. And being there, they offer the least possible hindrance to the movements of the body in general. ${ }^{2 \mathrm{I}}$

In implementing his programme, Aristotle uses these two ways in which corresponding parts of animals are related to divide the animal kingdom into nine major families along the following lines:

Some may find it surprising that everyday usage has not combined the wateranimals and the feathered animals into a single group, and adopted one name to cover both, since these two groups have certain features in common. The answer is that in spite of this the present classification is the right one, because while groups that differ only 'by excess' (that is, 'by the more and less') are placed together in a single group, those which differ so much that their characteristics are only analogous are separated out groups. For example: one bird differs from another bird 'by the more and less', or 'by excess': one bird's feathers are long, another's are short; whereas the difference between a bird and a fish is greater, and their correspondence is only by analogy: a fish has no feathers at all, but scales, which correspond to them. ${ }^{22}$

Then, in the History of Animals, Aristotle conducts an extensive and meticulous survey of the parts of animals working systematically through the different parts that he has identified, noting in each case the similarities and differences between the corresponding parts in different species of animals. Against that background, he will then in Books II to IV of the Parts of Animals attempt explanations of what his survey has shown.

We may conclude this survey by seeing how such explanations look in the particular case by taking a case where both kinds of comparison are combined in a single part. On the one hand, the elephant's trunk differs by the more and less from the human nose, and on the other is related by analogy to the human hand:

For the most part, there is very little variation in the organ of smell among the viviparous quadrupeds.... In the elephant this part is unique in its

${ }^{21} P A$ III 663a 34-663b i2. ${ }^{22} P A$ I 644a, I 2-23. 
extraordinary size and nature. Using its nostril as though it were a hand, the elephant conveys food, both solid and liquid, to its mouth, and it uses it to uproot trees by winding it round them. In effect it puts it to all the uses to which a hand is put. The reason for this is that the elephant has a double character, both as a land-animal and as a water-animal. It needs to get its food from the water, but at the same time must breathe, being a blooded land-animal. However, because of its great size, it cannot move rapidly from water to land, as do some other blooded vivipara that breathe. Thus it needs to be equally at home on land and in the water. In the same way, then, that divers are sometimes equipped with an instrument for breathing, giving them access to air from the surface while they are under water, so that they may remain for a long period under the sea, nature has provided the elephant with its elongated nose. ${ }^{23}$ Whenever they cross deep water, they lift their trunks up to the surface and breathe through it. For, as I have already said, the elephant's trunk is actually a nose. Now it would not have been possible for the nostril to discharge all these functions if it had not been soft and pliable. For then its sheer length would have prevented it from feeding, in the same way that the horns of certain oxen do, so that they are obliged to walk backwards while grazing. Thus it is soft and flexible, and because it is such, nature has, in her usual way, exploited this by assigning to it an extra function as well as its primary one - it performs the function of forefeet. In polydactylous quadrupeds, the forefeet do not merely support the animal; they serve as hands. But elephants (which, having neither a cloven hoof nor a solid hoof, must count as belonging to this group) are so huge and heavy that their forefeet are reduced to mere supports; and, indeed, because they move so slowly and bend with such difficulty, they are quite unfit for any other purpose. A nose, then, is given to the elephant for breathing, in the same way that one is given to every lunged animal; this is at the same time elongated and capable of being coiled round things, because the elephant spends so much of the time in the water, and takes time to move onto dry land. And since the forefeet are unable to fulfil the normal function of forefeet, nature, as I said, assigns to this part the rôle of discharging the function that should have been performed by the forefeet. ${ }^{24}$

Here we see the peculiarities of the elephant's trunk explained in terms both of its interrelationship with the other parts of the elephant and of its life and environment. Because it needs to be able to wade across water, it needs to breathe when it is submerged. Because of its bulk, it cannot readily bob in and out of the water in the way that, say, otters do. Therefore its breathing organ is an elongated flexible tube which can be used as a snorkel. At the same time, because of its bulk its legs must be like

${ }_{23}$ For modern evidence that Aristotle was right on this point, see West (200I), pp. I-8.

${ }^{24}$ PA II 658b 2-659a 37. 
pillars. Therefore it is unable to provide itself with forepaws. Therefore it exploits its trunk, as a long and flexible tube, shaped in such a way that it can form an analogy of an arm and hand.

What this example shows, as do many of Aristotle's examples, both in The Parts of Animals and elsewhere, is the way in which Aristotle's quest for teleological explanation leads to what can be described in modern terms as a sophisticated form of 'adaptationism' - an interplay between three different forms of adaptation: the way the parts of animals are adapted to the animal's environment, the way they are adapted to its way of life, and the way the parts of the animal are adapted to one another. Of course, Aristotle's understanding of such adaptation was quite different from postDarwinian adaptation developed in the context of a theory of natural selection: for Aristotle this was, rather, a consequence of the 'metaphysical' principle that 'Nature always works for the best'. What is also dubious is his apparently taking the further step of thinking that there must be a similar teleological explanation of why a particular species of animal exists.

Although the method of comparative biology that he has evolved depends upon comparing animals that are related only by analogy, the resulting arguments are not arguments by analogy in the sense that interests us in this book, but a form of what we would now call 'arguments to the best explanation'. Thus, Aristotle asks 'Why, in every species, no matter how morphologically different their eyes, are the eyes always located in the head of the animal?', and goes on to argue that this is explained by the fact that it is this placing of the eyes that is best suited for them to carry out their function in enabling the animals to take in their surroundings.

\section{Argument by Analogy}

Despite the extensive explorations of the concept of analogy that we find in Aristotle, arguments by analogy are comparatively uncommon. The clearest cases that we find are those in which he exploits analogies between animals and other complex entities such as the city state or, even, in the Poetics tragedy. In particular, he is concerned with the question 'In what way are such entities integrated and united as a single thing?'

If we return to Aristotle's conception of animals as substances, on his account animals are united as a single entity in a way that is quite different from the way in which a rock, say, is a single thing. In both cases we can talk of them as entities with parts, but for Aristotle this is so in completely different ways. A rock is a continuous lump of uniform material with a surface separating what is inside from what is outside the rock and a part of 
the rock is any continuous lump of material wholly contained within the surface of the rock. However, when Aristotle talks of the parts of substances, such as animals, he conceives of such parts quite differently. Here the parts are identified by their function in enabling the whole to flourish: eyes are the part that enables a man to see, etc. An animal is then to be seen as a system of such parts, organised in such a way as to permit the animal successfully to live out its life cycle. The way the parts are organised for this to be possible is the form of a substance. In the case of a living being this is its 'soul' ( $\psi \cup \times \grave{\eta})$ : that form of organisation that permits it to live.

In this way, an Aristotelian substance is dependent upon the proper functioning of its parts for its successfully continuing to thrive. The contrasts between such a substance and another entity such as a rock and between an Aristotelian part and a material part is sharp. What unifies a rock as a single entity is its being a continuous piece of matter, with clear boundaries. What unifies an animal as a single entity is its being a system of parts that cooperate to produce something that can live. If a material part is cut out of a rock, it simply continues to exist as a smaller rock. If an Aristotelian part of an animal is removed or damaged, the whole animal is impaired or disabled. Anything that can be removed or damaged without affecting the whole animal is not to be counted as a part of that animal.

In the light of this account, we can see how Aristotle models his account of the structure of tragedy, and in particular what it is for a tragedy to be a unified whole by transferring elements of that account. Having first argued for the centrality of plot in his account of tragedy, at I450a 39 he establishes an analogy between a tragedy and a living organism as follows:

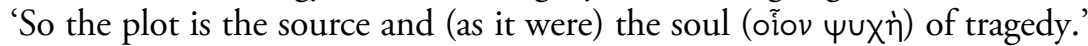

Aristotle will then pursue this analogy in his accounts of both the 'magnitude' and above all the unity of a tragedy:

Any beautiful object, whether a living organism or any other entity composed of parts, must not only possess those parts in proper order, but its magnitude also should not be arbitrary; beauty consists in magnitude as well as order. ... ${ }^{25}$

A plot is not (as some think) unified because it is concerned with a single person. An indeterminately large number of things happen to any one person, not all of which constitute a unity. ... Just as in other imitative

${ }^{25}$ Poe I450b, 35-38. Translation from Malcolm Heath, Aristotle, Poetics, Penguin Books Ltd., London 1996. 
arts the imitation is unified if it imitates a single object, so too the plot as the imitation of an action, should imitate a single, unified action - and one that is also a whole. So the structure of the various sections of the events must be such that the transposition or removal of any one section dislocates and changes the whole. If the presence or absence of something has no discernible effect, it is not a part of the whole. ${ }^{26}$

We see here Aristotle directly redeploying by analogy principles from his account of living organisms in his analysis of tragedy: that which makes a successful tragedy being understood by analogy with that which makes a healthy animal.

There is a major problem still to address. Let us suppose that we have established that $\mathrm{A}$ is an analogical model of $\mathrm{B}$, and that $\mathrm{A}$ has feature $\mathrm{F}$. How do we know whether $F$ is one of the features of $A$ that can be transferred to B? Within Euclid answering this question was straightforward. A series of a priori geometrical proofs can prove which features of similar triangles must be shared, and which need not be. However, once we consider arguments by analogy, no such a priori proofs are possible, and need replacing with empirical answers to this question. What makes one uneasy about Plato's use of analogy is that he nowhere addresses this issue.

In the case of Aristotle, there is one passage which needs to be considered in this connection, with two reservations: although the argument he considers can clearly be presented as an argument by analogy, he himself

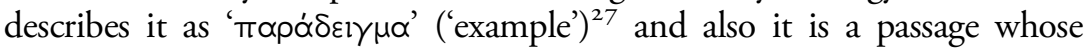
interpretation is controversial. This is Prior Analytics, II/24 (68b 39-69a I9).

Let A be 'bad', B 'to make war on neighbours', C 'Athens against Thebes' and $\mathrm{D}$ 'Thebes against Phocis'. Then if we require to prove that war against Thebes is bad, we must be satisfied that war against neighbours is bad. Evidence of this can be drawn from similar examples, e.g., that war by Thebes against Phocis is bad. Then since war against neighbours is bad, and war against Thebes is against neighbours, it is evident that war against Thebes is bad. Now it is evident that B applies to C and D (for they are both examples of making war on neighbours), and $\mathrm{A}$ to $\mathrm{D}$ (since the war against Phocis did Thebes no good); but that $\mathrm{A}$ applies to $\mathrm{B}$ will be proved by means of $\mathrm{D}$.

This is extraordinarily compressed. Cast as an argument by analogy it would run: 'War by Thebes against Phocis is bad. Thebes is to Phocis as

${ }^{26}$ Poe I451a, I6-35.

27 Aristotle presents 'example' as a type of proof that is neither deductive (syllogistic) nor inductive, since it is an inference from a single particular situation to another different particular situation. 
Athens is to Thebes (both being neighbours). Therefore war by Athens against Thebes is bad.' If this argument is to go through, we need to consider Aristotle's justification: 'we must be satisfied that war against neighbours is bad. Evidence of this can be drawn from similar examples, e.g., that war by Thebes against Phocis is bad.' As it stands, this is inadequate, and fails to do justice to what Aristotle has in mind in his discussions of 'example': we are meant to discern a general truth in a clearly understood particular case. However, the facts that Thebes waged war against Phocis, that Thebes and Phocis were neighbours and that this turned out badly for Thebes does not as yet suggest the general truth that going to war against a neighbour will turn out badly. To arrive at the general truth, we need also what Aristotle fails to capture, some link between the fact that Thebes and Phocis were neighbours and that the war turned out badly: what we need is for the example to show why it is bad to make war against a neighbour. The task of replacing Aristotle's inadequate formulation with something more precise lies ahead of us. In fact it is not until the end of the eighteenth and beginning of the nineteenth centuries that we find attempts being made to resolve that task, and we shall be turning to that towards the end of the next chapter.

\section{Retrospect: Analogical Models and Argument by Analogy}

\section{Analogy within Mathematics}

We may conclude this chapter by looking again at the most important feature of the use of analogy for our purposes: the beginnings of the idea of argument by analogy as understood in the context both of classical Greece and, we shall argue, the interpretation of Darwin's argument in the first four chapters of the Origin. Many facets of the concept of analogy that we have encountered in this chapter will recur throughout this book - such as, for example, Aristotle's stress on the capacity of analogical comparisons to compare 'things that are remote' (a drought is related to the plants in its region as a farmer is to the livestock in his care). However, our central concern is specifically with the concept of argument by analogy and the related idea of an analogical model. We shall therefore trace through what happens to these concepts in the period we have been looking at.

We may, somewhat artificially, divide the development of the examination of the concept of analogy during this period into three stages: the first stage is the analysis of the concept itself; the second stage is the extension of the concept within mathematics to give us the idea of an analogical 
model and the rigorous treatment of the simplest form of argument by analogy; and the third stage is the exploration of the question how far the ideas that have been developed within mathematics can be transferred into the empirical domain.

For our purposes, we may regard the first stage as Eudoxus' solution to the problem of incommensurable magnitudes. The discovery that there were cases where the relative magnitude of two lines could not be expressed as the ratio of two whole numbers meant that a different approach to the question of magnitude was necessary. Eudoxus' solution was to replace the attempt to express the relative magnitude of two lines by means of a closed arithmetical formula, by instead giving an account of the conditions under which the relative magnitude of two lines $\mathrm{A}$ and $\mathrm{B}$ equals the relative magnitude of two lines $\mathrm{B}$ and $\mathrm{C}$. That is to give the truth conditions of the formula $A / B=C / D$. This is given a precise account in Euclid V, definition 5, and in definition 6 such a relation is called 'analogous'. This understanding of the analogical formula is fixed at the outset, and will remain constant throughout the enquiry. Book $\mathrm{V}$ will then explore further properties of the analogical relationship, such as proving that analogies alternate (If $\mathrm{A} / \mathrm{B}=\mathrm{C} / \mathrm{D}$ then $\mathrm{A} / \mathrm{B}=\mathrm{C} / \mathrm{D}$.) This clearly provides a general theory of magnitude, applicable not only to lines, but also to areas, volumes, times, etc.

The next stage builds in Book VI on the account of analogy in Book V, to give us the most straightforward case of argument by analogy in the theory of similar triangles. We have here two triangles $\mathrm{ABC}$ and $\mathrm{A}^{\prime} \mathrm{B}^{\prime} \mathrm{C}^{\prime}$ such that there is a series of analogical relations between the sides of the triangles: $\mathrm{AB} / \mathrm{A}^{\prime} \mathrm{B}^{\prime}=\mathrm{AC} / \mathrm{A}^{\prime} \mathrm{C}, \mathrm{AB} / \mathrm{A}^{\prime} \mathrm{B}^{\prime}=\mathrm{BC} / \mathrm{B}^{\prime} \mathrm{C}^{\prime}$ and $\mathrm{AC} / \mathrm{A}^{\prime} \mathrm{C}^{\prime}=\mathrm{BC} / \mathrm{B}^{\prime} \mathrm{C}^{\prime}$. This gives us the simplest of all cases of analogical objects: two domains of elements, with a series of analogies between the various elements in one domain and the corresponding elements in the second domain. We can now construct a series of arguments by analogy, proving which properties are invariant under analogy - which may be transferred from the model to its target, and, equally importantly, which may not. (If two lines $l$ and $m$ in the model are parallel, then the corresponding lines $l$ 'and $m$ 'in the target will be parallel; corresponding angles will be equal; however, the size of areas, say, will not be preserved.) What we have here is a paradigm case of a fully valid set of arguments by analogy, where it is possible to develop purely a priori arguments to show what is and what is not invariant under analogy. This account can easily be extended from similar triangles to any geometrical configurations whatever, giving us a general theory of scale models. 


\section{Analogy beyond Mathematics}

In the final stage, possibly beginning with the Pythagorean mathematician, Archytas of Tarentum, there are explorations of the possibilities opened up if we extrapolate the idea of analogy from the mathematical to the empirical domain. For this, we take the formula 'A is to B as $\mathrm{C}$ is to $\mathrm{D}$ ' - or more explicitly, '(ARB = CRD)' but now interpret the formula, according to context, with a variety of different accounts of the relation ' $R$ '. This possibility was taken up and developed, even if in very different ways by both Plato and Aristotle.

\section{Plato}

We find extensive use of analogies in Plato. For instance, in the Republic, we have 'the divided line'28, 'the cave'29, and the overarching analogy of the Republic itself as an analogical model for the tripartite soul. Many of these are difficult to interpret in detail, and many of them are put forward purely to illustrate an idea rather than present arguments by analogy. The one that is clearly presented as an argument is the comparison between the ideal republic and the tripartite soul, aiming to show that it is better for someone to be just than unjust. However, these arguments are at best suggestive, and it always remains controversial whether Plato is justified in thinking that there is a genuine analogy that would justify the inference that we are invited to make.

\section{Aristotle}

We find a far more disciplined use of analogy in Aristotle. Three ideas dominate his discussions, each of which can be seen as having some relevance for our discussions throughout this book. There is a stress on the difference between analogy and simple similarity, with the claim that analogical comparisons are 'scientifically' more illuminating than comparisons based on common intrinsic properties of two things, since the latter comparisons are typically trivially obvious. Next there is an emphasis on the idea that it is analogy that gives us the capacity to make significant comparisons between 'things that are remote' (e.g. in different categories). Finally, Aristotle shows by example the way in which analogy can be used to throw light on or solve problems in a wide variety of fields, ranging from

${ }^{28}$ Republic, 509d-5ire. ${ }^{29}$ Republic, 514a-520a. 
justice to metaphor to biology - in general, wherever we want to explore the relation between 'incommensurable' entities.

Argument by analogy is far less frequent than in Plato - the most obvious examples being his application by analogy of his account of substance to other complex entities such as the state or tragedy, and scattered remarks - mostly in the Organon - concerning what he calls

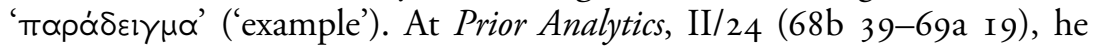
gives what may be regarded as the first attempt to give a theoretical account of the form of such arguments. 